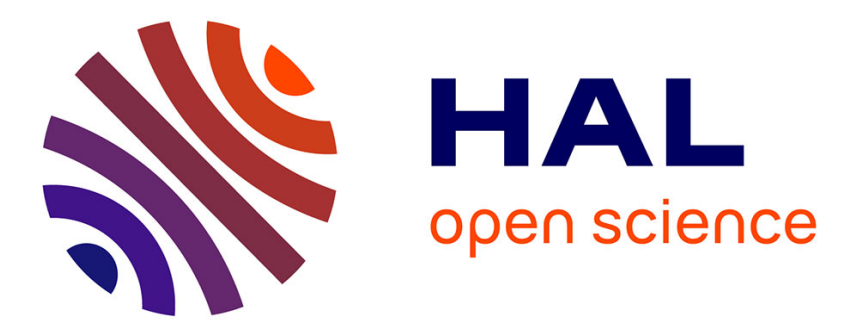

\title{
Electromyographic evaluation of the spontaneous and drug-induced motility of the cervix in sheep.
}

\author{
Rafael Garcia Villar, P.L. Toutain, Y. Ruckebusch
}

\section{To cite this version:}

Rafael Garcia Villar, P.L. Toutain, Y. Ruckebusch. Electromyographic evaluation of the spontaneous and drug-induced motility of the cervix in sheep.. Journal of pharmacological methods, 1982, 7, pp.83-90. hal-02720626

\section{HAL Id: hal-02720626 \\ https://hal.inrae.fr/hal-02720626}

Submitted on 1 Jun 2020

HAL is a multi-disciplinary open access archive for the deposit and dissemination of scientific research documents, whether they are published or not. The documents may come from teaching and research institutions in France or abroad, or from public or private research centers.
L'archive ouverte pluridisciplinaire HAL, est destinée au dépôt et à la diffusion de documents scientifiques de niveau recherche, publiés ou non, émanant des établissements d'enseignement et de recherche français ou étrangers, des laboratoires publics ou privés.

\section{()(1)(2)}

Distributed under a Creative Commons Attribution - ShareAlike| 4.0 International 


\title{
Electromyographic Evaluation of the Spontaneous and Drug-induced Motility of the Cervix in Sheep
}

\author{
R. Garcia-Villar, P. L. Toutain, and Y. Ruckebusch
}

Recordings of electrical activity of the cervix were obtained in cycling and ovariectomized ewes that were fitted with extracellular electrodes and strain gauge transducers. Spontaneous electrical and mechanical events occurred with a typical cyclic pattern. Methods of evaluation of drug action on the cervix are suggested with respect to the observed spontaneous cyclic activity of the organ.

Key Words: Electrical activity; Strain gauge transducers; Uterine cervix; Sheep; Oxytocin

\section{INTRODUCTION}

Electromyography has been extensively used in various species for the assessment of motor events of the uterus, and a relationship has been found between electrical and mechanical activity (Bass and Callantine, 1964). Variations in spontaneous uterine motility of the ewe at the time of estrus and prior to parturition have also been monitored with chronically implanted electrodes (Ruckebusch and Buéno, 1976; Prud'homme and Bosc, 1977). The increase in spontaneous electrical activity during an estrous period closely reflects the pattern of activity recorded using intrauterine balloons (Jones and Knifton, 1975); the increase in electrical activity of the uterus prior to parturition was in close agreement with the results obtained from pressure sensitive radio transmitters within the uterus throughout parturition (Hindson et al., 1968).

In contrast, for the cervix, no precise studies on motility have been made. Chen et al. (1966) tried to measure the changes in activity of the cervix in cows by inserting needle electrodes into the organ via vagina; they observed periods of activity during estrus that were enhanced by oxytocin. The majority of physiologic studies on the cervix have been made measuring elastance prior to parturition (Fitzpatrick and Dobson, 1979), because it was assumed that dilatation was the major physiologic event of this organ at this time. The paucity of data on spontaneous motility of the cervix can be explained by the fact that histologic studies have revealed that the cervix is composed mostly of connective tissue and, consequently, intrinsic muscular activity was not considered important. However, the cervix is composed of

From Station de Pharmacologie-Toxicologie, I.N.R.A., 31300 Toulouse, France.

Address reprint requests to Dr. R. Garcia-Villar, Station de Pharmacologie-Toxicologie, I.N.R.A., 180 chemin de Tournefeuille, 31300 Toulouse, France.

Received August 1981; revised and accepted September 1981. 
an outer layer of longitudinal smooth muscle and a zone of connective tissue with smooth muscle cells embedded in the collagen.

The aim of the present work was to detect, by electromyography, variations in the motility of the cervix in cyclic and ovariectomized ewes and to determine the relationship between electrical and mechanical activity. In addition, we have suggested optimal conditions and criteria of evaluation for the assessment of drug action, using oxytocin as an example.

\section{METHODS}

The experiments were conducted during the breeding season using 6 nonpregnant, parous, 3- to 4-year-old ewes weighing between 45 and $58 \mathrm{~kg}$. Ewes were of the Lacaune breed, a species in which the breeding season is particularly long. After being fasted for 2 days the ewes were subjected to a low mid-line laparotomy under general anesthesia (thiopental sodium, $20 \mathrm{mg} / \mathrm{kg}$, induction and $4 \%$ halothane). Electrodes were made from insulated nichrome wires, $0.12 \mathrm{~mm}$ in diameter and $200 \mathrm{~cm}$ in length (Trinamel: Johnson Matthey Metals Ltd, London). They were inserted using a needle as a trocar through the walls of the cervix and each of the uterine horns, $2 \mathrm{~mm}$ apart in groups of three. The free end was tied off close to the wall and the electrodes were exteriorized through an incision on the flank. A strain gauge transducer $(2 \times 1 \mathrm{~cm})$, oriented with the long axis of the cervical canal, was sutured between the two groups of cervical electrodes. Another gauge was similarly fixed in close proximity to the group of electrodes on the uterine horn. Four groups of electrodes were fixed in each ewe, two along the cervical canal at a distance of $4 \mathrm{~cm}$, and one on each uterine horn. The length of the electrode wires and the connecting cables of the gauges allowed the animals to lie down and move freely in a cage without risk of damage to the recording apparatus. Two of the six ewes were ovariectomized.

The electrical activity was monitored throughout the experiment by connecting two of the three electrodes of each group to a polygraph (RC coupling, time constant $0.1 \mathrm{sec}$, Reega, Alvar, Paris). The paper speed ranged from $0.5-20 \mathrm{~cm} / \mathrm{min}$ for direct recording. From the polygraph, output signals were continuously plotted at $20 \mathrm{sec}$ intervals, using a linear integrator circuit (Latour, 1973) connected to a potentiometric recorder (chart speed of $6 \mathrm{~cm} / \mathrm{hr}$ ). To assess the relationship between electrical and mechanical activities, both were simultaneously recorded using a rectilinear pen polygraph (strain-gauge coupler type 9803, Beckman Instr. Inc).

Twenty-four hours following surgery, direct recordings were made for several hours each day during diestrus in cycling and ovariectomized ewes. However, around the period of estrus, recordings were made continuously. Permanent integration of records occurred for the entirety of all experiments ( 3 to 5 months).

The synthetic desamino-oxytocin (ODEAX, Biochimie $\mathrm{GmbH}$, Austria) was administered intravenously (iv) at a therapeutically recommended dose rate ranging from 0.1 to $10 \mathrm{IU}$ in toto. 


\section{RESULTS}

\section{Electrical Activity}

The recording of electrical activity was carried out for at least 3 months in each ewe. The cycling ewes exhibited a normal estrous cycle, as was judged by an increase in the activity from the uterus over a period of $48 \mathrm{hr}$ at 3 week intervals.

For both cycling and ovariectomized ewes the electrical activity consisted of two different signals with respect to duration and amplitude: i) a signal of short duration (less than $0.25 \mathrm{sec}$ ) and high amplitude $(200$ to $500 \mu \mathrm{V})$, consisting of single spikes (SS) or of very short spike bursts (SSB). SS and SSBs occurred either isolated (Fig. 1a) or in a series at a frequency of $12-20 / \mathrm{min}$ during 4 to $7 \mathrm{~min}$ (Fig. 1b); ii) a signal of long duration (10 to $20 \mathrm{sec}$ ) and low amplitude (less than $50 \mu \mathrm{V}$ ), consisting of a burst of potentials and thus termed long spike bursts (LSB). LSBs were recorded more rarely and without any apparent regularity in their occurrence (Fig. 1c).

Integrated recordings of the spiking activity showed cyclic peaks of high amplitude that corresponded to the occurrence of a series of SS and SSB. These peaks were preceded by an interval of long duration in which isolated SS, SSB, and LSBS were intermingled (Fig. 1 integrated). This typical pattern of cervical activity recurred at an interval of 30 to $90 \mathrm{~min}$. In contrast to uterine activity, the cyclic activity of the cervix persisted throughout the estrous cycle in cycling ewes and for more than 5 months in ewes that were ovariectomized.

\section{Mechanical Activity}

In all cases, a close relationship existed between electrical and mechanical activities. During isolated SS or SSBs, variations in muscular activity of the cervix of relatively long duration (5-8 sec) and small amplitude $(2-4 \mathrm{~g})$ were recorded from the strain gauge. Consequently, when SS and SSBs occurred in series, the mechanical activity of each isolated SS and SSB was summated, whence the baseline was elevated (5-10 g) for 4 to $7 \mathrm{~min}$ (Fig. 2). The rate of increase (slope) of this baseline was directly related to the frequencies of the electrical signals. During LSB the mechanical activity was of long duration and high amplitude (Fig. 2).

This mechanical profile of the cervix was recorded independently of the activity of the uterus. During diestrus only the cervix displayed this period of prolonged activity at 60-90 min intervals. At the end of estrus the periods of cervical activity were frequently associated with those of the uterus at intervals of approximately $30 \mathrm{~min}$. As shown in Figure 2, the frequencies of contraction of the uterine horn at the onset of estrus were very regular and the value of 3-5 per min differed from that of the cervix.

\section{Induced Motor Changes}

The existence of a spontaneous motility pattern in the cervix must be taken into account when drug action is assessed and three points deserve attention: i) the time of injection; ii) the criteria used to evaluate changes in motility in terms of electrical or mechanical activity and in terms of patterns of organization; and iii) 


\section{DIRECT}

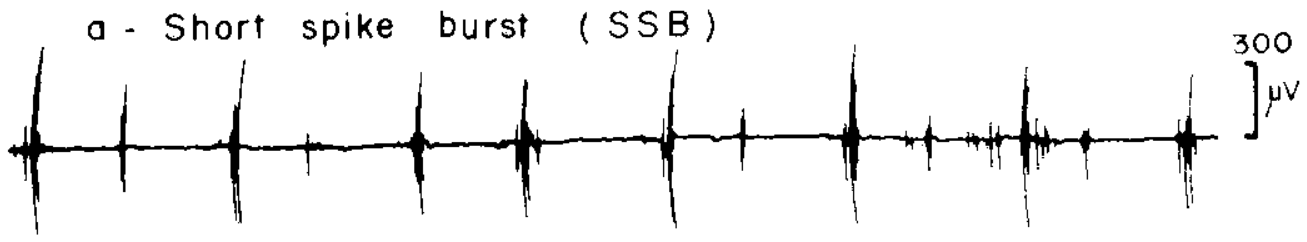

b - Series of SSB
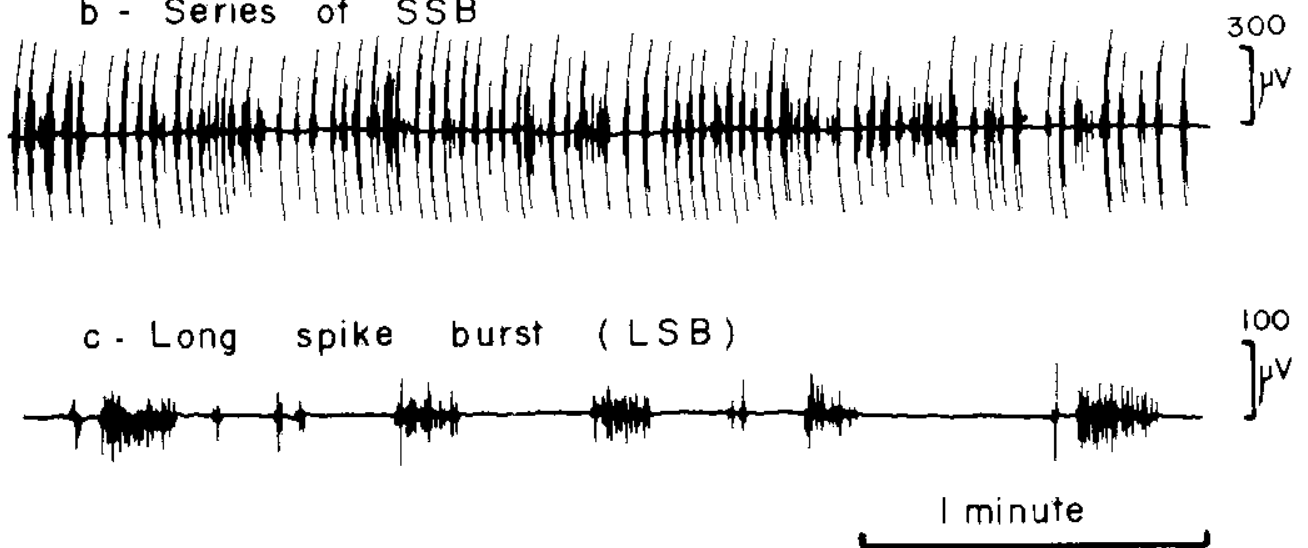

INTEGRATED

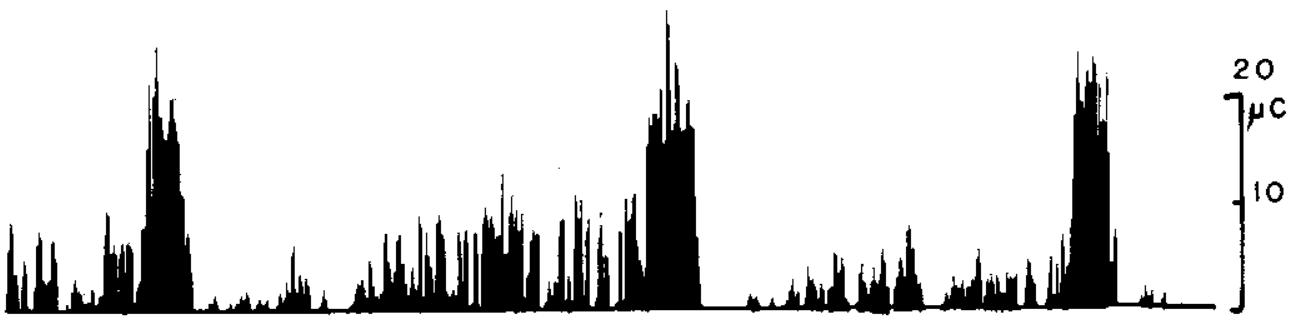

I nour

FIGURE 1. Patterns of electrical spiking activity of the ovine cervix. Short spikes (SS) and short spike bursts (SSB) of high amplitude are recorded either isolated (a) or in series (b); long spike bursts (LSB) of low amplitude occur randomly (c). The integration of the spiking activity at regular intervals of 20 sec shows a cyclic increase in the activity corresponding to a series of SS and SSB at hourly intervals. 

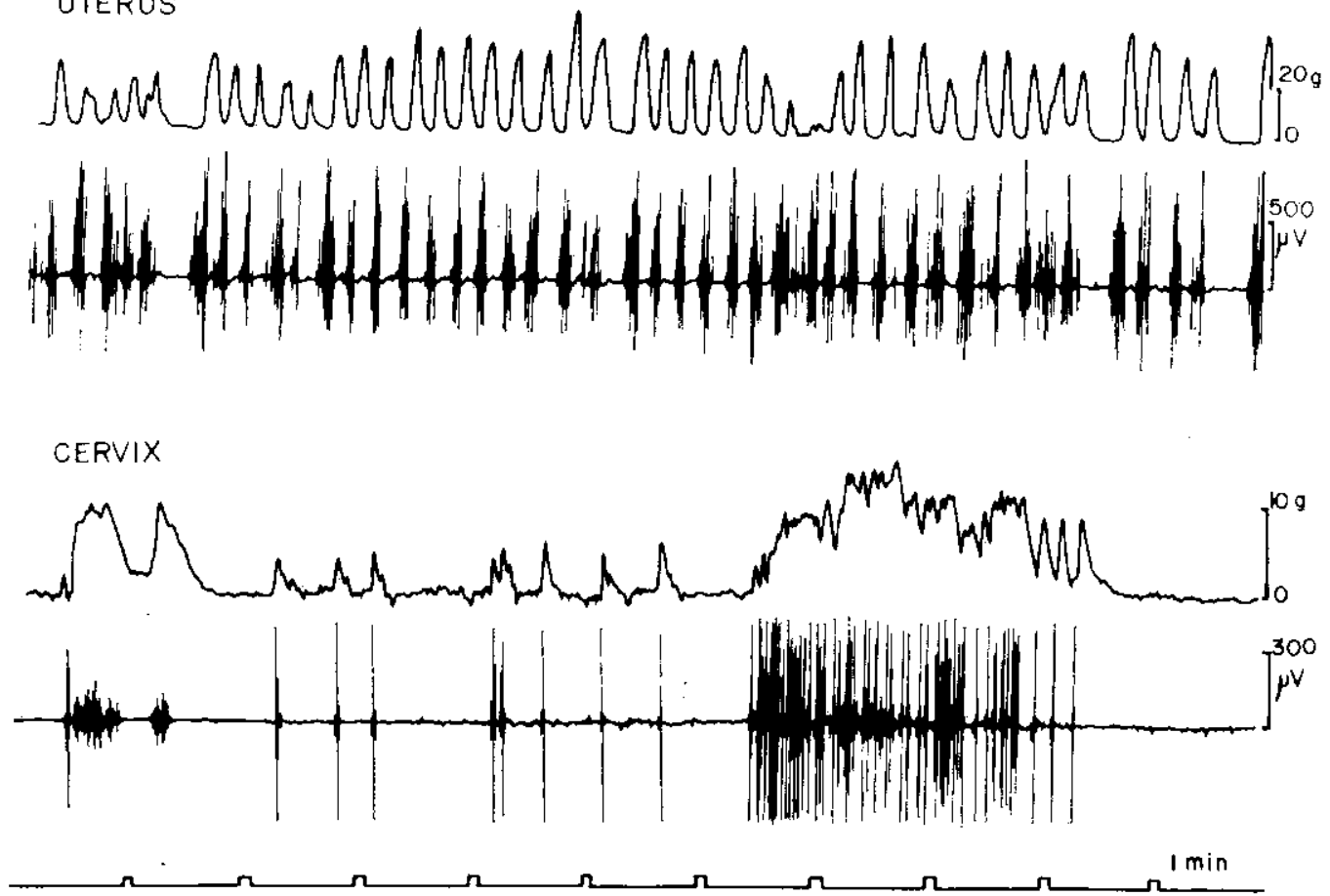

FIGURE 2. Electrical and mechanical activities of the uterus and the cervix. In the estrous ewe, contractions of the uterine wall occur regularly at a frequency of 3-5 per min, while those of the cervix follow a cyclic pattern, including a series of SSB preceded by isolated LSB and SSB.

the evaluation of the termination of drug action. The selected time of injection is of considerable importance and differs according to whether the drug is excitatory or inhibitory in its action. Intervals between each series of SS or SSB were always higher than $20 \mathrm{~min}$; consequently a delay of $10 \mathrm{~min}$ after a series of SS or SSB is optimal to test an excitatory drug without the interference of spontaneous activity. In contrast, a delay of 2 min after the commencement of a series of SS and SSB provides the most adequate condition for evaluating an inhibitory drug, especially if the duration of action is short. The evaluation of the drug action can be made according to different criteria in both direct and integrated records. In a direct record, action can be described in terms of frequency and amplitude of the different electrical and mechanical signals. In the integrated record, eventual modification of the normal pattern was evident and is described in terms of suppression, disorganization, etc. If the commencement of the effect is always easy to evaluate, the total duration is more difficult to assess as the drug action decreases progressively. In all cases, the recovery of the normal pattern of rythmicity of the series of SS and SSBs was considered as the true end of the drug action. 
As an example of the useful application of direct and integrated electromyographic recordings, the action of oxytocin at different dosage regimens is presented. Figure 3 shows the effect of $1 \mathrm{IU}$ of oxytocin. In the direct record a series of SS and SSBs with a mean spiking frequency of 16.5 per min was seen for 7-10 min and resembled a normal series, after which a shorter series of progressively longer intervals occurred for approximately $100 \mathrm{~min}$. The return to the control pattern was seen approximately $2 \mathrm{hr}$ postinjection. When the delay in return-tonormal was used as the criteria of drug action, it appeared as a dose-dependent effect, as shown in Figure 4. The injections were performed in the four ewes in estrus.

\section{DISCUSSION}

As far as we know the long-term spontaneous and drug-induced activity of the cervix has not previously been studied in vivo and hence an electromyographic technique for this purpose is useful. The technique is simple and allows investigation on the same animal over a long period of time without the interference produced by the repeated insertion of intracervical balloons or other devices. The close correlation between electromyographic signals and mechanical events allowed the electromyographic signal to be used as an index of cervical motility; the
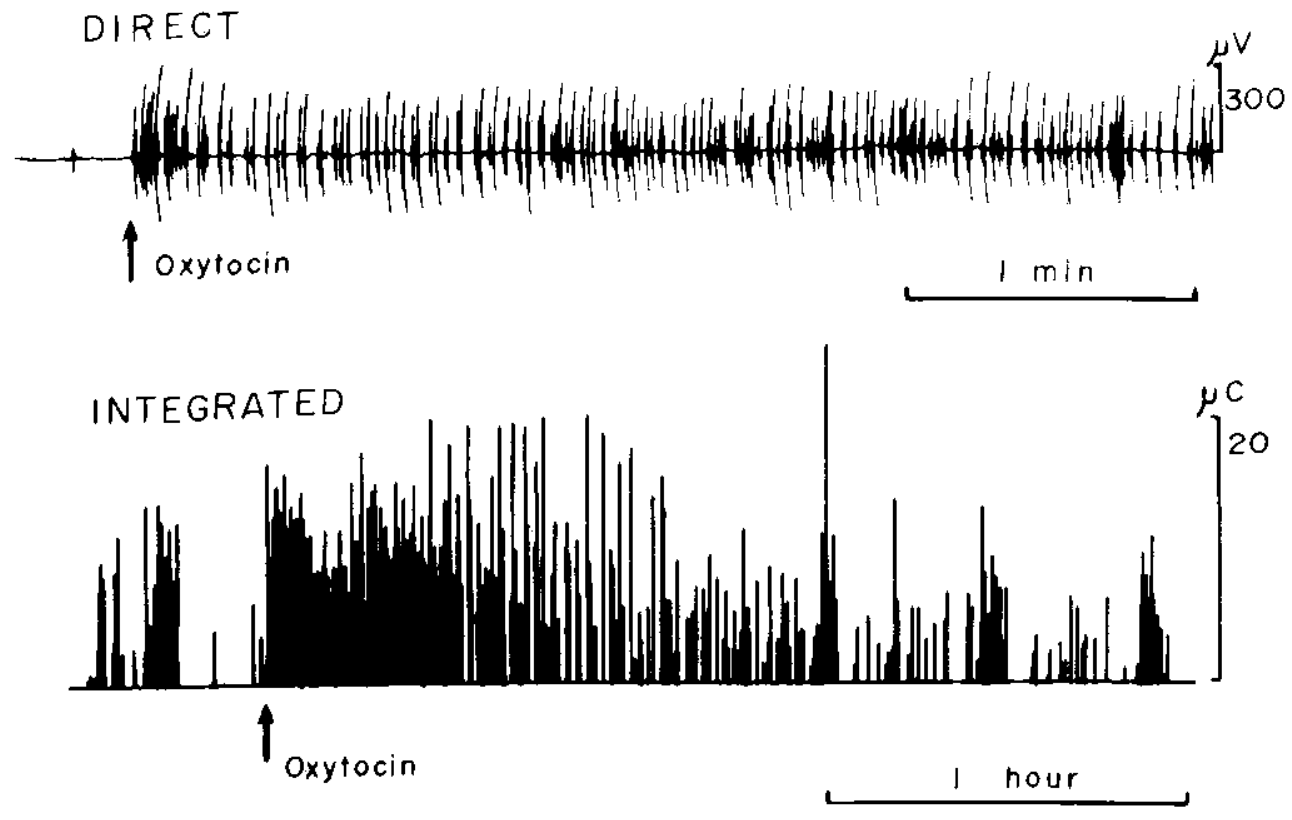

FIGURE 3. Response of the ovine cervix to intravenously administered desamino-oxytocin (ODEAX) in an estrous ewe. The short-term effect consists of an increase in activity lasting 5 to $7 \mathrm{~min}$ for $1 \mathrm{lU}$ (direct record) and the return-to-normal pattern is reached within $90 \mathrm{~min}$ (integrated record). 


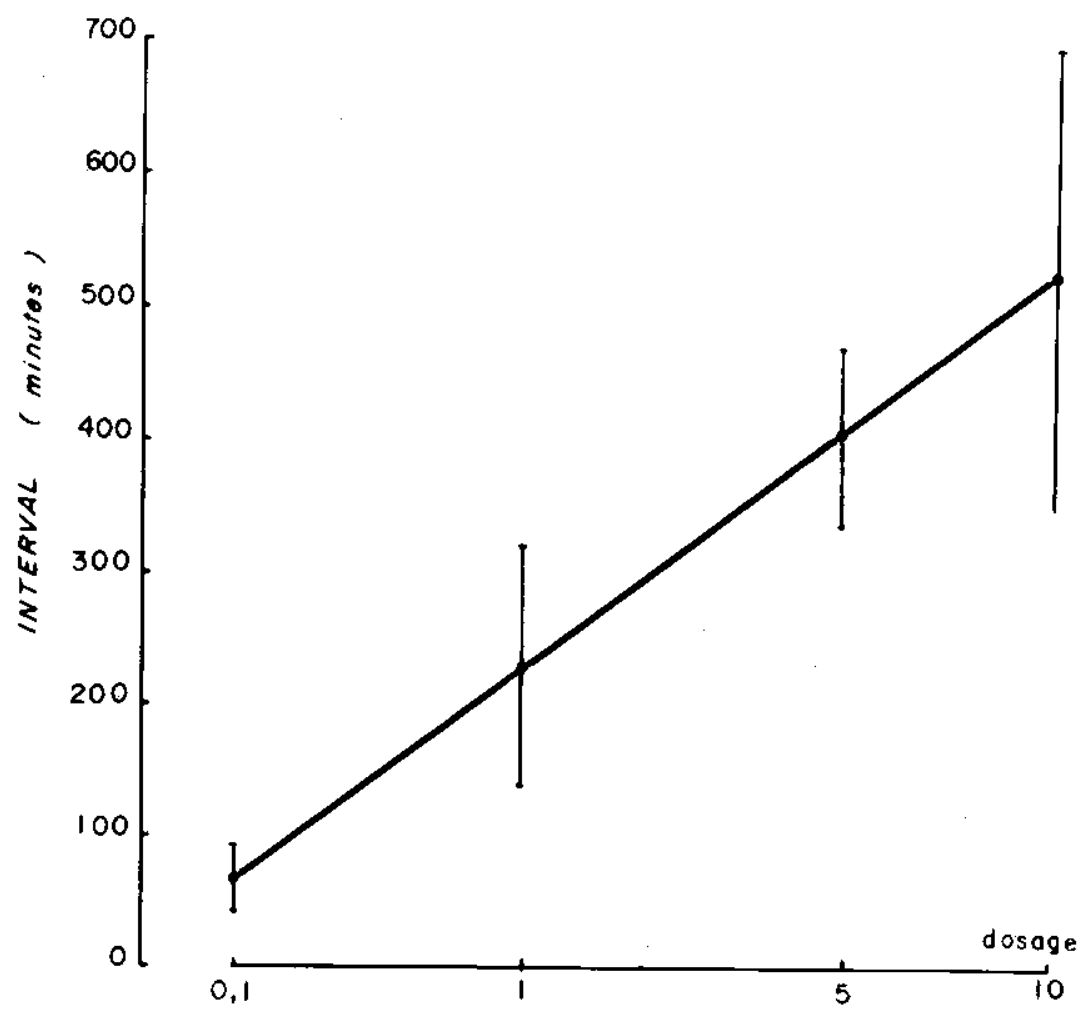

FIGURE 4. Dose-related effect of the intravenous administration of desamino-oxytocin (ODEAX) to 4 ewes in estrus (weight range 45 to $51 \mathrm{~kg}$ ). The dose rates range from 0.1 to 10 IU per animal. Data are means \pm SD for at least 2 injections per animal and per dose. The delay or interval of recovery $(V)$ is related to the dosage $(\log X)$ by the equation $Y=227.2$ $\log X+292$.

most striking feature revealed by both electromyography and the force transducer was the existence of a spontaneous activity, organized as a cyclic pattern, independent of the animal's hormonal status, e.g., estrus, diestrus, and following ovariectomy. In contrast, activity in the uterus was only present around estrus and disappeared progressively after ovariectomy. The period of the cyclic activity in the cervix was between 30 and $90 \mathrm{~min}$, depending upon the hormonal status; for example, at the end of estrus, the period of cervical cycles was short ( $30 \mathrm{~min})$ and synchronized with the activity of the uterus.

The presence of spontaneous activity must be considered when drug actions are assessed. A delay of $10 \mathrm{~min}$ after the occurrence of a series of SS and SSBs seemed to be optimal for the appreciation of the effects of an excitatory drug. Conversely, suspected inhibitory compounds must be administered 2 min after the onset of a series of SS and SSB. The short-term effects of drugs are easily evaluated on direct records, but integrated records are necessary to appreciate the long-term effects 
and the occurrence of the return-to-normal pattern. Oxytocin offered a good example. Using direct recording, an immediate strong effect of short duration was seen during $10 \mathrm{~min}$ but the return-to-normal pattern was delayed until $2 \mathrm{hr}$ postinjection. Consequently, such a delay must be observed before the injection of another drug.

Our technique offers several advantages in the measurement of ovine cervix motility. The small and flexible electrodes do not distort the cervical canal or interfere with its motility. Integration of the spike potentials allows an easy identification of regular and rhythmic changes that are also well-defined by a strain gauge fixed in the vicinity of the electrodes. Knowledge of the cyclic pattern of activity of the cervix is a prerequisite for the quantitation of drug action on the organ. Further utilization of this model to provide qualitative and quantitative data on the pharmacological reactivity of the cervix in both pregnant and nonpregnant animals is recommended.

This research was supported by the Institut National de la Recherche Agronomique (FRANCE), animal pathology department. The authors gratefully acknowledge the helpful collaboration of Dr. T. HACHET for the setting of strain gauge transducers and Mrs G. COSTES and Mr M. CAUSSETTE for the iconography.

\section{REFERENCES}

Bass P, Callantine MR (1964) Simultaneous recording of electrical and mechanical activity of the uterus in the unanesthetized animal. Nature (Lond) 203:1367.

Chen TW, MacDonald MA, Hawes RO (1966) Mechanical and electrical activities of the female bovine genital tract in-vivo. Can / Anim Sci $46: 25-29$.

Fitzpatrick RJ, Dobson H (1979) The cervix of the sheep and goat during parturition. Anim Reprod Sci 2:209-224.

Hindson JC, Schofield BM, Turner CB (1968) Parturient pressures in the ovine uterus. $/$ Physiol (Lond) 195:19-28.

Jones DE, Knifton A (1975) Spontaneous and oxytocin-induced uterine motility during the estrus cycle in goats, Res Vet Sci 19:131-134.

Latour A (1973) Un dispositif simple d'analyse quantitative de l'électromyogramme intestinal chronique. Ann Rech Vet 4:347-353.

Prud'homme MJ, Bosc MJ (1977) Motricité utérine de la brebis, avant, pendant et aprés la parturition spontanée ou aprés traitement par la dexaméthasone. Ann Biol Anim Bioch Biophys 17:9-19.

Ruckebusch $Y$, Buéno L (1976) An electromyographic study of the uterotubal activity in the ewe. I Reprod Fertil 47:221-227. 